\title{
Biogenic synthesis of silver nanoparticles mediated by Acinetobacter indicus and its biomedical applications
}

\author{
M. Ezhilvanan and S.F. Lesley Sounderraj* \\ Department of Zoology, Voorhees College, Vellore, Tamilnadu, India \\ *Corresponding author
}

\section{A B S T R A C T}

\begin{tabular}{l} 
Key w or d s \\
$\begin{array}{l}\text { Acinetobacter } \\
\text { indicus, Biogenic, } \\
\text { Larvicidal, } \\
\text { Nanotechnology, } \\
\text { Silver nanoparticles }\end{array}$ \\
\hline Article Info \\
$\begin{array}{l}\text { Accepted: } \\
\text { 25 September } 2019 \\
\text { Available Online: } \\
\text { 10 October } 2019\end{array}$ \\
\hline
\end{tabular}

Nanotechnology, an attractive branch of science deals with smaller particles with incredible efficiency. The applications of nanoparticles were widely distributed in all fields of science to enhance the reaction with ease. Despite of chemical and physical method of synthesis, biological methods has gained importance due to its less toxicity and cost efficiency. In the present study, silver nanoparticles (Ag NP's) were synthesized using the culture supernatant of AcinetobacterindicusVLE-1 isolated from paper mill effluent. The synthesized nanoparticles were characterized using UV- visible spectroscopy, FTIR, XRD, SEM and TEM analysis. Biogenic Ag NP's were evaluated for its antagonistic ability against selected pathogenic bacterial strains such as Bacillus cereus, Streptococcus pyogenes, Shigella dysentriae, Escherichia coli and Proteus vulgaris. Maximum zone of inhibition was recorded against Escherichia coli and Shigella dysentriae when compared with the control. The nanoparticles were determined for its larvicidal activity against Culex mosquito larvae at various concentrations. Larvicidal activities were observed to be directly proportional to the concentration of biogenic Ag NP's.

\section{Introduction}

Nanoparticle is a unique subset of the extensive scientific research area called as nanotechnology. Nanoparticles are those particles ranging in size from $10 \mathrm{~nm}$ to 100 nm. Currently, they are gaining importance due to its use vast array of applications such as medicine, drug delivery, information, energy and environmental technologies (Murphy, 2008). Nanoparticles can be classified into two types viz engineered nanoparticles and non-engineered nanoparticles. Engineered nanoparticles are those created or synthesized artificially such as silver nanoparticles, gold nanoparticles etc for their use in several techniques where as non-engineered nanoparticles are those that are freely available in the environment such as atmospheric nanoparticles that are produced during combustion, aerosols etc. Both engineered and non-engineered nanoparticles pose their uses in several industries (Wagner et al., 2014). Several techniques have been developed to synthesize nanoparticles such as chemical mediated synthesis, gas and liquid phase process etc. Despite the above mentioned "Bio-mediated (Biogenic) synthesis" of nanoparticle has been growing from last decade to develop eco-friendly 
technologies in material synthesis. Biosynthesis of nanoparticle from microorganisms, enzymes, fungus, and plants or plant extracts has been considered as animpeccable alternative for the chemical mediated synthesis due to their cheap cost and economically benign nature (Phanjom et al., 2012). Further the chemical and physical synthesis of nanoparticles was found to involve hazardous materials that impart toxic impact to environment (Okuyama et al., 2004).

Microbial synthesis of nanoparticles is considered to be a highly efficient process since it involves biological entity in synthesis, its cost effective and it does not impart any side effects to both biotic and abiotic factors. Several microorganisms such as Pseudomonas stutzeri(Klaus et al., 1999), Escherichia coli (Du et al., 2007), Serratia marcescens (Karthika et al 2015), Shewanellaalga (Konishi et al., 2007), Chromohalobacter salexigens (Tharanya et al 2015), Yeast cells, Actinomycetes sp., (Thirumangai et al., 2015), etc.have been explored for the synthesis of nanoparticles. Nature has opened several ways for fabricating nanoparticles in smaller size. In 1999, Klaus and his co-workers demonstrated bacterial mediated biosynthesis of nanoparticles after identifying the accumulation of silver inside the bacterial cell (Klaus et al., 1999). Reduction of metal ions to form nanoparticles by bacteria extracellularly may occur using any one of the two methods. Reduction may occur by the involvement of biomolecules liberated by the bacterial cells into the culture medium or the bacterial cell itself may for the nanoparticles inside the cell wall and liberate it outside the system (Mahdieh et al., 2012). Interestingly, reduction of metal ions into nanoparticles can also be mediated in the absence of cell biomass, that is the bacterial supernatant can be used for the synthesis of nanoparticles that comprises of active biomolecules secreted by the bacteria. In the present study, silver nanoparticles have been synthesized by bacterial species and their characterization has been performed. This study highly emphasizes on the antagonistic efficacy of bacterial mediated silver nanoparticle against the selected clinical pathogens and larvicidal efficacy of synthesized material against Culex mosquito larvae.

\section{Materials and Methods}

\section{Sample Collection}

Effluent samples were collected from paper mill contaminated sites in and around Erode, Tamilnadu. Samples were collected in sterile polythene containers and transported to laboratory aseptically to avoid contamination. The transferred samples were kept in air tight container and stored in refrigerator at $4^{\circ} \mathrm{C}$ for future use.

\section{Isolation of bacterial strains}

Samples were serially diluted to varying concentration and about $0.5 \mathrm{ml}$ of the diluted sample were plated on freshly prepared nutrient agar plate maintaining at $\mathrm{pH}$ 7. The agar plates were incubated at $37^{\circ} \mathrm{C}$ for $48 \mathrm{~h}$ in an incubator. Following incubation, morphologically distinct colonies (size, shape and color) were selected and streaked over the above-mentioned medium until pure cultures were obtained. The pure colonies were designated as VLE 1 to VLE 3and maintained as glycerol stock at $4{ }^{\circ} \mathrm{C}$ for further use.

\section{Synthesis of Silver Nanoparticle}

To $100 \mathrm{ml}$ of freshly prepared nutrient media, loopful cultures of the isolates (VLE-1 to VLE-3)were inoculated and incubated at $37^{\circ} \mathrm{C}$ for $24 \mathrm{~h}$ in shaking incubator at $150 \mathrm{rpm}$. Following incubation, the grown cultures were centrifuged at 10,000 for 15 minutes. The 
supernatantswere stored in a sterile screw cap tube for synthesis of nanoparticles. To $10 \mathrm{ml}$ of culture supernatants, $5 \mathrm{ml}$ of silver nitrate $\left(\mathrm{AgNO}_{3}\right)$ solution $(10 \mathrm{mM})$ was added and incubated at $30{ }^{\circ} \mathrm{C}$ for $24 \mathrm{~h}$. Control was maintained without the addition of culture broth. Both the test solutions were kept in dark to avoid undesired photochemical reactions during the study. After $24 \mathrm{~h}$ of incubation, the solutions were observed for colour change from yellow to reddish brown which confirms the formation of AgNP's. The silver nanoparticles (Ag NP's) were purified by centrifugation at 10,000 rpm for 5 min twice, and the samples were collected for further characterizations(Karthika et al., 2015). The potential strain was further subjected to phenotypic, microscopic and morphological identification.

\section{Characterization of biogenic Ag NP's UV-Vis Spectroscopy}

The efficiency of biogenic approach in reducing $\mathrm{Ag}$ ions was evident by the appearance of brown colour which confirms the formation of silver nanoparticles in reaction mixture. The solution was subjected to measuring the absorbance against distinct wave lengths to confirm the formation of silver nanoparticles using UV-Vis Spectroscopy. Formation of silver nanoparticles is easily detected by spectroscopy since the coloured nanoparticle solution shows a peak at $\sim 400 \mathrm{~nm}$. In this study, Jasco spectrophotometer (V-730) was used to measure the optical density of solution (Pugazhendhi et al., 2017).

\section{Fourier Transform Infra-Red Spectroscopy (FTIR)}

To remove any free biomass residue or compound that is not capping the ligand of the nanoparticles, after complete reduction, synthesized silver nanoparticles were concentrated by repeated centrifugation (3 times) at $15,000 \mathrm{rpm}$ for $20 \mathrm{~min}$. The supernatant was replaced by distilled water each time. Thereafter, the purified suspension was freeze dried to obtain dried powder. The dried biogenic nanoparticles were made into $\mathrm{KBr}$ pellet and the functional groups were analysed using ALPHA FT-IR Spectrometer (from Bruker, Germany). Presence of various functional groups were determined by viewing peaks between the region $4000 \mathrm{~cm}^{-1}$ to 500 $\mathrm{cm}^{-1}$ (Guan et al., 2018).

\section{X- Ray Diffraction (XRD) Analysis}

The reduced solution was centrifuged at 8000 rpm for $40 \mathrm{~min}$ and resulting supernatant was discarded and pellet obtained was re-dispersed in deionized water. Non-adsorbed substances were removed from the nanoparticles by repeated centrifugation. Thus, obtained pellet was purified and dried. The dried pellets were subjected to X-ray diffraction (XRD) analysis. For XRD studies, dried Ag NP's were coated on XRD grid, and the spectra were recorded by using Phillips PW 1830 instrument operating at a voltage of $40 \mathrm{kV}$ and a current of $30 \mathrm{~mA}$ with $\mathrm{Cu} \mathrm{K} \alpha 1$ radiation (Sadhasivam et al., 2012).

\section{Scanning Electron Microscopy (SEM)}

The particle size and morphology of the silver nanoparticles were examined using Scanning Electron Microscopic observations. SEM measurements were performed on a JEOL JSM 6390 instrument operated at an accelerating voltage at $15 \mathrm{kV}$. The sample was sonicated prior to examination for uniform distribution(Tharanya et al., 2015).

\section{Transmission Electron Microscopic analysis}

The synthesized nanoparticles were subjected to TEM analysis for determining its size and 
morphology. The biogenic Ag NP's were measured using Transmission electron microscopy - Hitachi H-7100) using an accelerating voltage of $120 \mathrm{kV}$ and methanol as solvent (Tharanya et al., 2015).

\section{Antibacterial activity:}

Antibacterial activity of biosynthesized AgNP's has been studied against the selected pathogenic strains Bacillus cereus, Streptococcus pyogenes, Shigella dysentriae, Escherichia coli and Proteus vulgaris. To determine the antibacterial efficacy of silver nanoparticles, Muller Hinton agar plates were made freshly and wells were made using sterile well cutter. The above-mentioned pathogenic strains were swabbed over the agar media using sterile cotton swab. Test wells were inoculated with synthesized biogenic $\mathrm{Ag}$ NP's $(100 \mu \mathrm{g} / \mathrm{ml})$ and controls were maintained. The plates were incubated in incubator at $37{ }^{\circ} \mathrm{C}$ for $24 \mathrm{~h}$ and left undisturbed. Following incubation, the plates were observed for zone of inhibition (mm) (Shanmuga Praba et al., 2015).

\section{Larvicidal activity of Biogenic Ag NP's against Culex mosquito}

Antagonistic activity of Ag NP's was investigated towards the Culex larvae. The above-mentioned samples were treated with varying concentration of $\mathrm{Ag}$ NP's ranging from $(10 \mu \mathrm{g} / \mathrm{ml}, 25 \mu \mathrm{g} / \mathrm{ml}, 50 \mu \mathrm{g} / \mathrm{ml}, 75 \mu \mathrm{g} / \mathrm{ml}$ and $100 \mu \mathrm{g} / \mathrm{ml}) .20$ late third and fourth instar larvae of Culex mosquitoes were collected from Department of Zonal Entomology, Vellore, Tamilnadu. Collected larvae were equally distributed in 5 sterile trays containing dechlorinated water with increasing concentration of synthesized Ag NP's. Average larval mortality in the test and control samples were observed after $24 \mathrm{~h}$ of incubation. Triplicates were maintained and the rate of mortality in percentage was calculated using the mortality formula
Mortality percentage $=$ No. of larvae killed / Total No. of Larvae tested X 100.

\section{Results and Discussion}

\section{Synthesis of Silver Nanoparticle}

Synthesis of silver nanoparticles were done using the bacterial cell free culture supernatant where, the supernatant was mixed with $5 \mathrm{ml}$ of $\mathrm{AgNO}_{3}(10 \mathrm{mM})$ and incubated for $24 \mathrm{~h}$. Following incubation, the reaction mixture was observed for visible color change where, the mixture has been changed to reddish brown from yellow color which confirmed the reduction of silver metal into silver nanoparticles. The suspension was completely dried on hotplate and powder form of the silver nanoparticles were collected.

\section{Identification and characterization of the isolate}

Among various colonies, single colony based on its ability to synthesis silver nanoparticle was selected and sub cultured on sterile nutrient media. The pure culture was subjected to microscopic, biochemical and molecular analysis. The isolate VLE-1 was found to be Gram negative coccobacillus in nature. The biochemical analysis of the isolate was tabulated in table 1 .

\section{Characterization of biogenic Ag NP's UV-Vis Spectroscopy}

UV- Visible absorption spectra of synthesized silver nanoparticles was subjected to UVVisible spectroscopic analysis between the range 350 to $600 \mathrm{~nm}$. Reduction of silver ions to silver nanoparticles was confirmed by visible color change of the reaction mixture from yellow (broth) to reddish brown (synthesized Ag NP's). In this study, absorption behavior arises due to surface plasmon resonance (SPR), was notices as 
sharp peak at $464 \mathrm{~nm}$ which shows the presence of silver nanoparticle in the sample (Fig 1).

\section{Fourier Transform Infra-Red Spectroscopy (FTIR)}

FTIR analysis of the synthesized silver nanoparticles (AgNP's) were carried out to determine the functional groups of active molecules involved in reducing and capping the silver metal to silver ions in the synthesized material. The FTIR spectra of the silver nanoparticle was shown in Fig 2in which the spectrum of the bacteria mediated silver nanoparticles exhibited transmittance band at $3259 \mathrm{~cm}^{-1}$ represents the presence of $\mathrm{O}-\mathrm{H}$ free bond, aldehyde C-H stretching (2953 $\mathrm{cm}^{-1}$ and $\left.2920 \mathrm{~cm}^{-1}\right)$. Peak at $1587 \mathrm{~cm}^{-1}$ corresponded to amide I, arising due to carbonyl stretch in proteins. Peak at $1041 \mathrm{~cm}^{-1}$ corresponded to $\mathrm{C}-\mathrm{N}$ vibrations of the amine. Hence, it proves that the synthesis of biogenic Ag NP's involving in the biological reduction of the $\mathrm{AgNO}_{3}$ was mediated by the bacterial metabolites.

\section{X- Ray Diffraction (XRD) Analysis}

X-ray diffraction is an important method to determine the nature of the synthesized material from the X-ray diffraction pattern. It enables to understand the structure of crystalline material and used for the lattice parameters analysis of single crystals, or the phase, texture or even stress analysis of samples. The crystal structure of the AgNP's was analyzed by X-ray diffractometer. Formation of silver nanoparticles synthesized using the culture supernatant of Acinetobacter indicus StrainVLE-1 was supported by X-ray diffraction measurements. X-ray diffractogram of synthesized AgNP's showed distinct diffraction peaks at $25.46^{\circ}, 31.90^{\circ}, 37.15^{\circ}$, $37.90^{\circ}, 38.73^{\circ}, 48.23^{\circ}, 54.07^{\circ}$, 55. $26^{\circ}$, $62.34^{\circ}, 62.87^{\circ}, 68.95^{\circ}, 70.45^{\circ}, 75.22^{\circ}$ and $76.20^{\circ}$ indexed to the planes $110,111,211$ and 220 (Fig. 3).

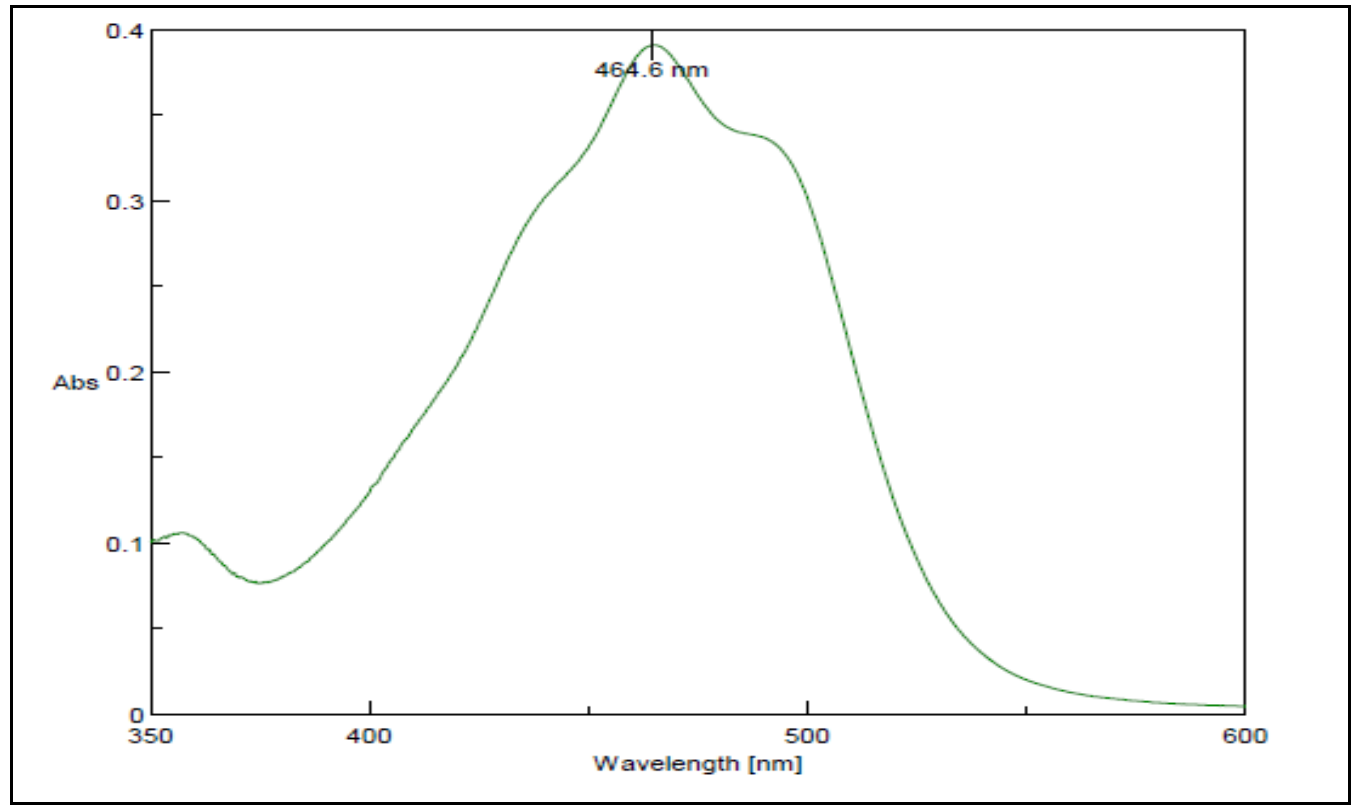

Fig.1 UV-Vis spectrum of Ag NP's biosynthesized using Acinetobacter indicus VLE-1 


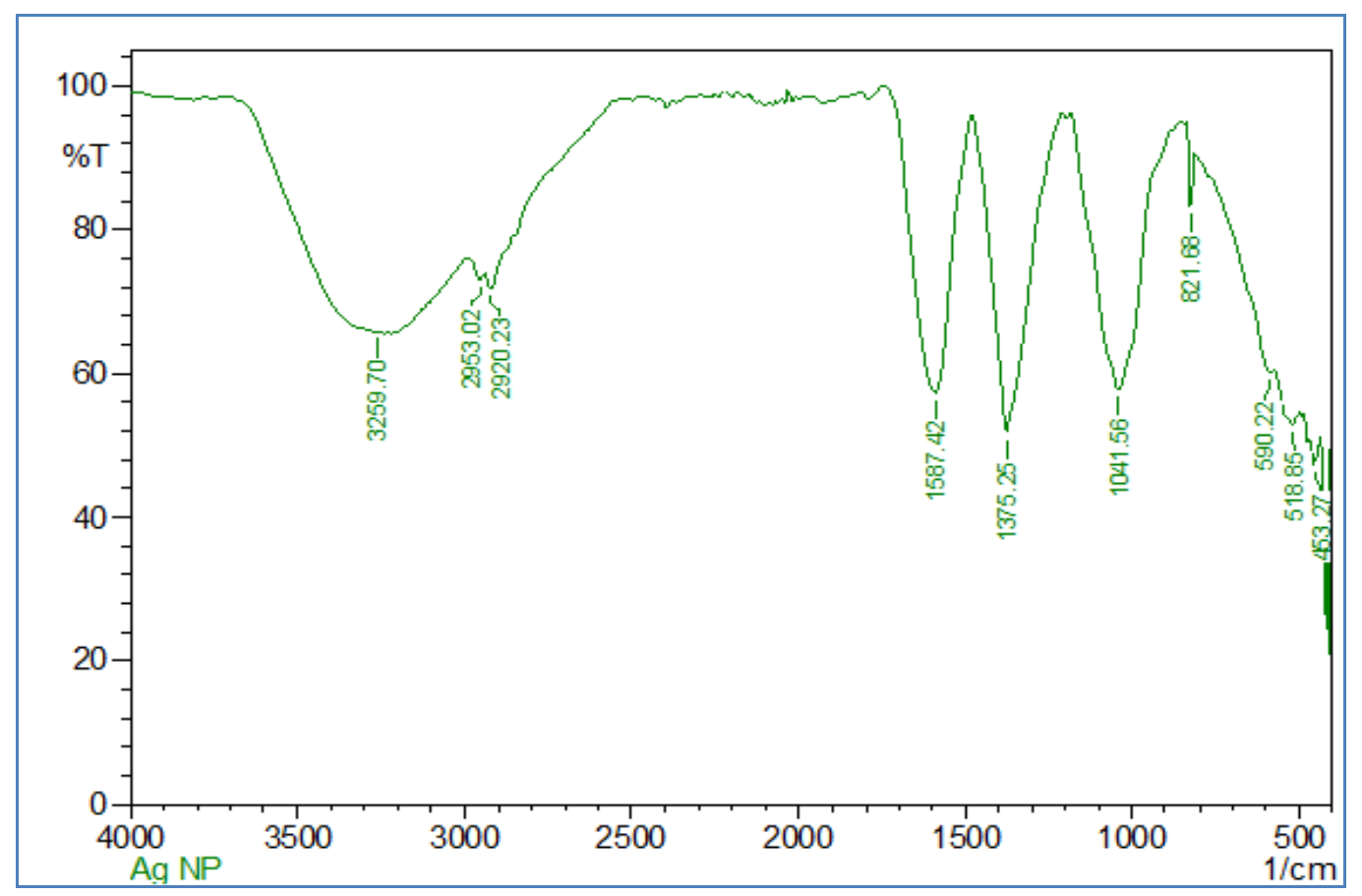

Fig.2 FTIR spectra of Ag NP's biosynthesized using Acinetobacter indicus VLE-1

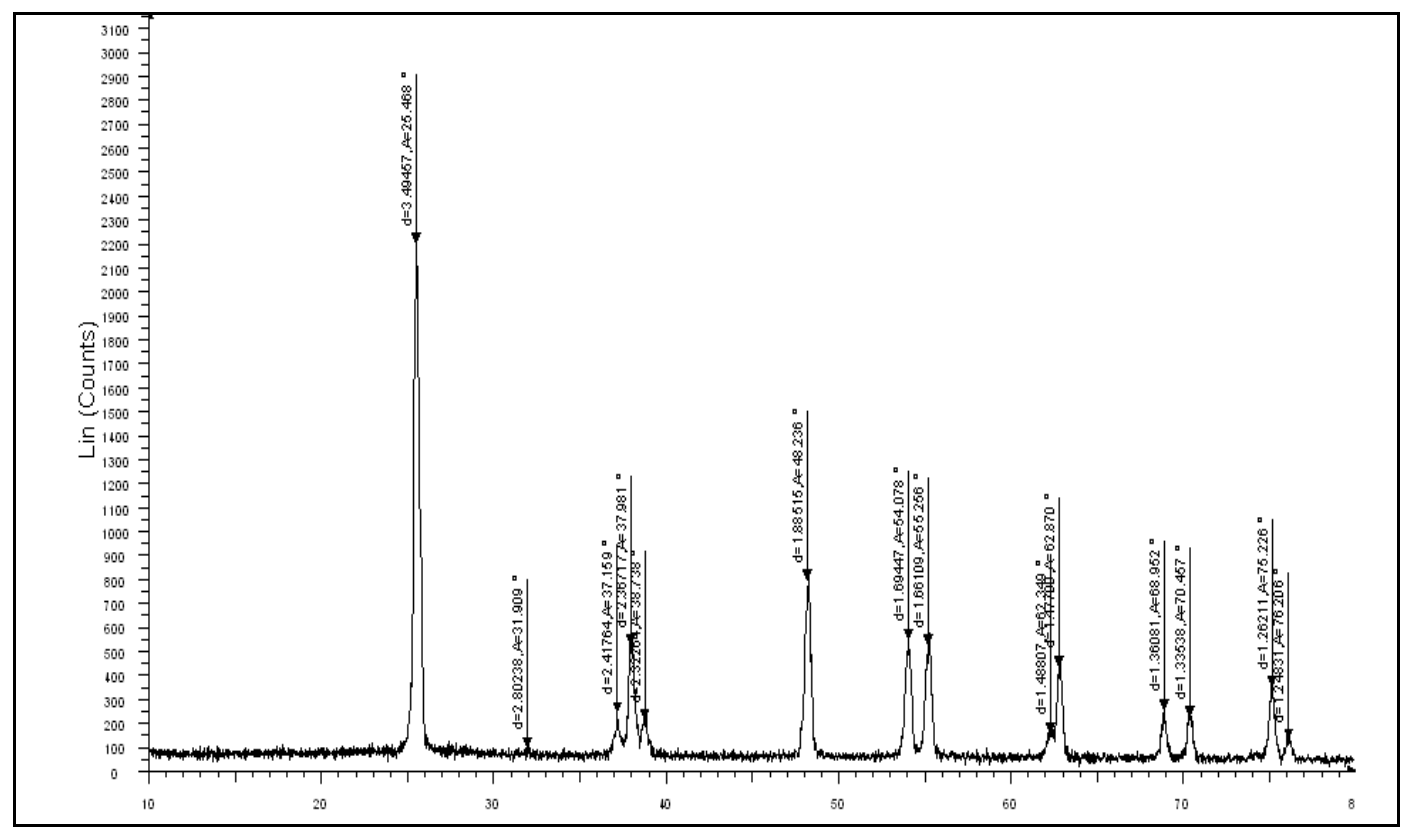

Fig.3 XRD analysis of Ag NP's biosynthesized using Acinetobacter indicus VLE-1 

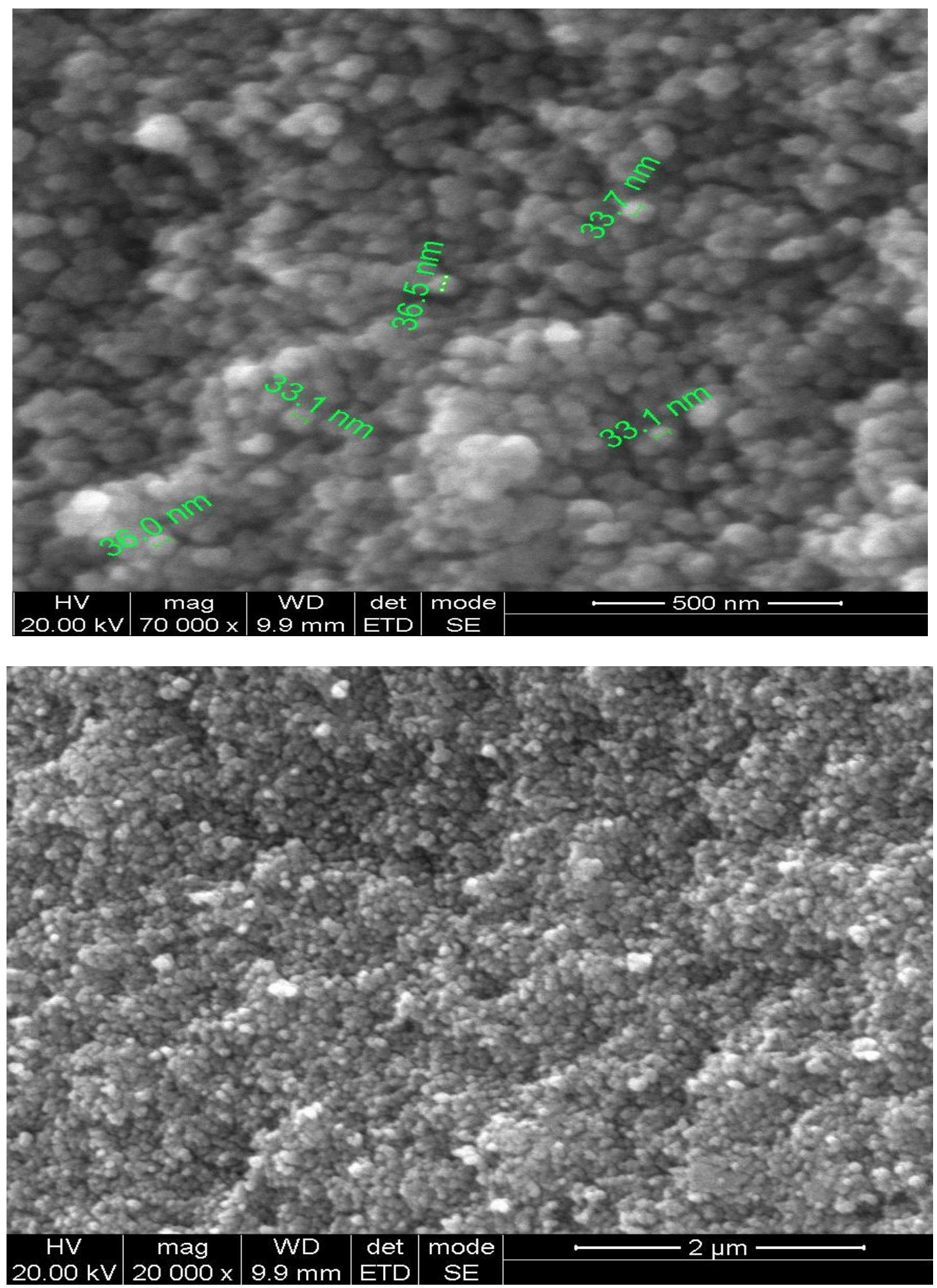

Fig.4 SEM Images of Ag NP's biosynthesized using Acinetobacter indicus VLE-1 

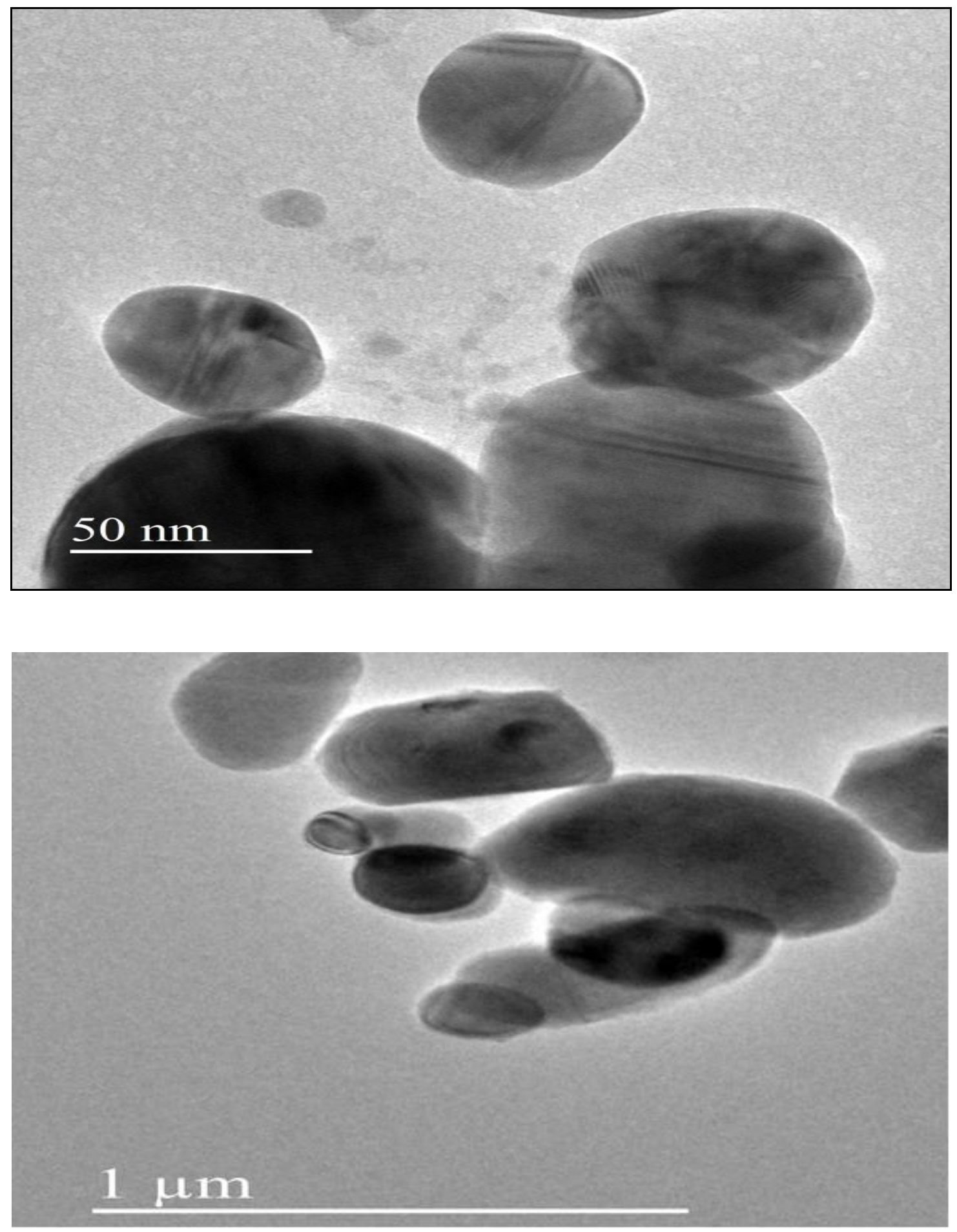

Fig.5 TEM Images of Ag NP's biosynthesized using Acinetobacter indicus VLE-1 
Table.1 Morphological, Physiological and Biochemical Characteristics of strain VLE-1

\begin{tabular}{|c|c|c|}
\hline S. No & Test & Observations \\
\hline 1 & $\begin{array}{l}\text { Morphology } \\
\text { Grams staining } \\
\text { Cell shape } \\
\text { Motility } \\
\text { Cell arrangement }\end{array}$ & $\begin{array}{l}\text { Negative } \\
\text { Cocco-bacilli } \\
\text { Non-Motile } \\
\text { Single, paired and short chains }\end{array}$ \\
\hline 2 & $\begin{array}{l}\text { Colony Characters on Nutrient agar } \\
\text { Colony morphology } \\
\text { Colony size } \\
\text { Colony elevation } \\
\text { Colony density } \\
\text { Colony edge } \\
\text { Pigmentation }\end{array}$ & $\begin{array}{l}\text { Spherical } \\
2.5-3.0 \mathrm{~mm} \\
\text { Raised } \\
\text { Dull, opaque } \\
\text { Entire } \\
\text { Greyish white }\end{array}$ \\
\hline 3 & $\begin{array}{l}\text { Sugar Fermentation } \\
\text { Lactose } \\
\text { Maltose } \\
\text { Glucose } \\
\text { Sucrose }\end{array}$ & $\begin{array}{l}\text { Negative } \\
\text { Positive -Acid } \\
\text { Positive -Acid } \\
\text { Positive-Acid }\end{array}$ \\
\hline 4 & $\begin{array}{l}\text { IMVIC } \\
\text { Indole } \\
\text { Methyl Red } \\
\text { Voges Proskauer } \\
\text { Citrate }\end{array}$ & $\begin{array}{l}\text { Negative } \\
\text { Positive } \\
\text { Positive } \\
\text { Negative }\end{array}$ \\
\hline 5 & $\begin{array}{l}\text { Enzyme Reaction } \\
\text { Urease Production } \\
\text { Catalase Activity } \\
\text { Oxidase } \\
\text { Coagulase }\end{array}$ & $\begin{array}{l}\text { Negative } \\
\text { Positive } \\
\text { Negative } \\
\text { Negative }\end{array}$ \\
\hline 6 & $\mathrm{H}_{2} \mathrm{~S}$ Production & Negative \\
\hline 7 & Caseinase Activity & Negative \\
\hline 8 & Gelatin & Negative \\
\hline
\end{tabular}


Table.2 Antibacterial activity of Ag NP's against selected bacterial pathogens

\begin{tabular}{|c|l|c|c|}
\hline \multirow{2}{*}{ S.No } & \multirow{2}{*}{ Bacterial pathogens } & \multicolumn{2}{|c|}{ Zone of Inhibition (mm) } \\
\cline { 3 - 4 } 1. & Bacillus cereus & Bio Ag NP's (100 $\mathbf{~ g g / m l )}$ & Standard Antibiotics \\
\hline 2. & Streptococcus pyogenes & $09 \pm 0.2$ & $14 \pm 0.2$ \\
\hline 3. & Shigella dysentriae & $11 \pm 0.3$ & $13 \pm 0.2$ \\
\hline 3. & Escherichia coli & $14 \pm 0.3$ & $13 \pm 0.1$ \\
\hline 4. & Proteus vulgaris & $15 \pm 0.2$ & $14 \pm 0.2$ \\
\hline
\end{tabular}

Table.3 Larvicidal activity of AgNP's synthesized using Acinetobacter indicus VLE-1

\begin{tabular}{|c|c|c|c|c|c|}
\hline \multirow{3}{*}{$\begin{array}{l}\text { Conc. of Ag } \\
\text { NP's }(\mu g / \mathrm{ml})\end{array}$} & \multirow{2}{*}{\multicolumn{3}{|c|}{$\begin{array}{c}\text { Mortality of larva after } 24 \mathrm{~h} \\
\text { Replica } \mathrm{N}=3\end{array}$}} & \multirow[t]{3}{*}{ Average } & \multirow{3}{*}{$\begin{array}{l}\text { Mortality } \\
(\%)\end{array}$} \\
\hline & & & & & \\
\hline & Trial 1 & Trial 2 & Trial 3 & & \\
\hline Control & 0 & 0 & 0 & 0 & 0 \\
\hline $10 \mu \mathrm{g} / \mathrm{ml}$ & 3 & 4 & 4 & 3.66 & 18.30 \\
\hline $25 \mu \mathrm{g} / \mathrm{ml}$ & 7 & 7 & 8 & 7.33 & 36.65 \\
\hline $50 \mu \mathrm{g} / \mathrm{ml}$ & 10 & 11 & 10 & 10.33 & 51.65 \\
\hline $75 \mu \mathrm{g} / \mathrm{ml}$ & 14 & 13 & 15 & 14.0 & 70.00 \\
\hline $100 \mu \mathrm{g} / \mathrm{ml}$ & 16 & 17 & 16 & 16.33 & 81.65 \\
\hline
\end{tabular}

\section{Scanning electron microscope (SEM)} analysis

The SEM images of AgNP's obtained with the culture supernatant of Acinetobacter indicus were also subjected for Scanning Electron Microscopy to determine the size and morphology of the synthesized nanoparticles.SEM analysis revealed that the average size of the nanoparticles ranged between $33.1 \mathrm{~nm}$ to $36.7 \mathrm{~nm}$ with interparticle space. The shape of the synthesized particles was observed to be spherical and ellipsoidal with uniform distribution (Fig4).

\section{Transmission Electron Microscope (TEM) analysis}

Morphological features of the synthesized silver nanoparticles were also investigated by TEM analysis and the results represents the size and distribution of the nanoparticles. The size determined using TEM shows the particles ranges from $20 \mathrm{~nm}$ to100 nm. This analysis also confirms that the synthesized silver nanoparticles were spherical and few with irregular shape (Fig 5).

\section{Antibacterial activity}

Antibacterial activity of the synthesized biogenic Ag nanoparticles was carried out by conventional Kirby-Bauer well diffusion method against Bacillus cereus, Streptococcus pyogenes, Shigella dysentriae, Escherichia coli and Proteus vulgaris. Silver nanoparticles exhibited maximum antagonistic activity towards Escherichia coli $(15 \mathrm{~mm})$ and Shigella dysentriae $(14 \mathrm{~mm})$ when compared with the standard antibiotics. Notable antagonistic effect was observed for Streptococcus pyogenes $(11 \mathrm{~mm})$,Proteus vulgaris $(10 \mathrm{~mm})$ and Bacillus cereus $(9 \mathrm{~mm})$ (Table 2). 
Larvicidal activity of Biogenic Ag NPs against Culex mosquito

Larvicidal activity of synthesized silver nanoparticles were studies against Culex mosquito larvae. Larvicidal activity of the nanomaterial increased with increasing concentration of biogenic Ag NP's. Mortality rate reached $50 \%$ at $50 \mu \mathrm{g} / \mathrm{ml}$ and highest rate of mortality was recorded at $100 \mu \mathrm{g} / \mathrm{ml}$. Interestingly, notable antagonistic activity of Ag NP's against Culex larvae was encountered at minimal concentration $(10 \mu \mathrm{g} / \mathrm{ml})$ with the rate of $18 \%$ and maximum concentration $(100$ $\mu \mathrm{g} / \mathrm{ml}$ ) kills larvae at the rate of $81.66 \%$ (Table 3). Thus, this shows that the synthesized Ag NP's at lower concentration also has the efficacy to kill the Culex mosquitoes at larval stages.

Silver nanoparticles has received tremendous significance among the several other nanoparticles due to its less toxicity, easy synthesis and higher applications in medicine and environmental applications. Biological methods of nanoparticle synthesishave gained much attention due to its compatibility to ecosystem when compared with the chemical methods. In this study, bacteria isolated from paper mill effluents samples were cultivated and the extracellular components were investigated for the synthesis of nanoparticle with antagonistic efficacy against clinical pathogens. Cell free supernatant of Acinetobacter indicuswas used for the synthesis of silver nanoparticles.Similarly, cell free supernatant of Thermoactinomycessp. was reported to synthesize spherical silver nanoparticle ranging from $20-40 \mathrm{~nm}$ in size (Deepa et al., 2013). Culture supernatant comprising nutrient broth and other bacterial metabolites enables the reduction of Ag metal to Ag nanoparticles. Knowledge about the reduction of silver ions and formation of silver nanoparticles were still not clear, but it is believed that protein molecules and enzyme, including nitrate reductase enzyme which may act as good regulating agent in the formation of silver nanoparticles.

Synthesis, formation and stability of nanoparticles are determined using UV-Vis spectroscopy. Excitation of SPV leads to the formation of AgNP's which was confirmed by the visible color change from yellow to reddish brown. This conversion remains as the signature feature of AgNP's in the solution (Chung et al., 2016). In the present study, synthesis of silver nanoparticle was confirmed by the presence of sharp peak at $464 \mathrm{~nm}$. Broad spectral length denotes the polydispersed silver nanoparticles. The reduction of silver ion to silver nanoparticles was confirmed by the peak between the respective spectral range. Similar results were recorded in the green synthesized silver nanoparticles where, leaf extract of $A$. indica were used and the plasmon resonance band was observed between 436 - $446 \mathrm{~nm}$ (Ahmed et al., 2015). FTIR results of the synthesized silver nanoparticle confirmed the presence of functional groups such as alcohols, aldehydes, amides and amines. Similar spectral results were reported by Sharma et al. (2018) in which silver nanoparticles were synthesized using plant extracts. Phase angle and crystalline nature of the synthesized bacteria mediated silver nanoparticles exhibited diffraction peaks at $25.46^{\circ}, 31.90^{\circ}, 37.15^{\circ}$, $37.90^{\circ}, 38.73^{\circ}, 48.23^{\circ}, 54.07^{\circ}, 55.26^{\circ}$, $62.34^{\circ}, 62.87^{\circ}, 68.95^{\circ}, 70.45^{\circ}, 75.22^{\circ}$ and $76.20^{\circ}$ indexed to the planes $110,111,211$ and 220. The synthesized nanoparticles were crystalline in nature. Anandan et al. 2019 also reported similar results from silver nanoparticles synthesized using aqueous leaf extract of Dodonaeaviscosa. Scanning electron microscopic analysis reveals that the particles were spherical and ellipsoidal with average size ranging from $33.1 \mathrm{~nm}$ to $36.5 \mathrm{~nm}$.

TEM analysis also confirmed that the Ag NP's 
were spherical and the size ranges within 100 $\mathrm{nm}$. Antibacterial activity of the synthesized nanoparticles exhibited maximum resistance towards Escherichia coli $(15 \mathrm{~mm})$ and Shigella dysentriae $(14 \mathrm{~mm})$. Notable antagonistic activity was found for other strains used in the study. Similarly, silver nanoparticles synthesized using Coffea arabica seeds exhibited effective antibacterial ability against E. coli and Staphylococcus aureus (Dhand et al. 2016). On the other hand, Ag NP's synthesized using banana peel extract expressed efficient antagonistic ability against Gram negative bacteria (E. coli and Pseudomonas aeruginosa) when compared with Gram's positive bacteria (Bacillus subtilis and Staphylococcus aureus) (Ibrahim, 2015). Larvicidal activity of biogenic silver nanoparticle were found to have higher potential in killing the Culex mosquito at larvae stage. The mortality was observed at both minimum $(10 \mu \mathrm{g} / \mathrm{ml})$ as well as maximum concentration $(100 \mu \mathrm{g} / \mathrm{ml})$. Mortality rate of Culex larvae was higher at $100 \mu \mathrm{g} / \mathrm{ml}$ $(81.65 \%)$.

Ever since the discovery of the first antibiotic Penicillin, bacterial community acquired resistance through various evading mechanisms. MDR against the bacterial pathogens has emerged as the most dreadful concern among the human population around the globe. This study embodies, an efficient invention which act as proficient antibacterial agent against infections caused by Bacillus cereus, Streptococcus pyogenes, Shigella dysentriae, Escherichia coli and Proteus vulgaris. Biogenic nanoparticles also remain as a potential antimicrobial agent that sensitize resistance against bacterial pathogens. This novel approach also aids to overcome drug resistance among pathogenic bacteria. These biogenic nanoparticles also mediate cytotoxicity via cell wall disruptions and possess larvicidal activity againstCulex mosquitoes. Hence, it is essential to focus on the developing applications of Ag NP's in environmental and medicinal sectors.

\section{References}

Ahmed, S., Ullah, S., Ahmad, M., Swami, B.L., 2015. Green synthesis of silver nanoparticles using Azadirachta indica aqueous leaf extract. J. Radiat. Res. Appl. Sci. 1-7. https://doi.org/10.1016/j.jpras.2015.06.006

Anandan, M., Poorani, G., Boomi, P., Varunkumar, K., Anand, K., Chuturgoon, A.A., Saravanan, M., Prabu, H.G., 2019. Green synthesis of anisotropic silver nanoparticles from the aqueous leaf extract of Dodonaea viscosa with their Antibacterial and Anticancer activities. Process Biochem. https://do.

https://doi.org/10.1016/j.procbio.2019.02.014

Chung, I., Park, I., Seung-Hyun, K., Thiruvengadam, M., Rajakumar, G., 2016. Plant-mediated synthesis of silver nanoparticles: their characteristic properties and therapeutic applications. Nanoscale Res Lett $11,40$.

Deepa, S., Kanimozhi, K., Panneerselvam, A., 2013. Antimicrobial activity of extracellularly synthesized silver nanoparticles from marine derived actinomycetes. Int J Curr Microbiol Appl Sci 2, 223-230.

Dhand, V., Soumya, L., Bharadwaj, S., Chakra, S., Bhatt, D., Sreedhar, B., 2016. Green synthesis of silver nanoparticles using Coffea arabica seed extract and its antibacterial activity. Mater. Sci. Eng. C 58, 36-43. https://doi.org/10.1016/j.msec.2015.08.018

Du, L., Jiang, H., Liu, X., Wang, E., 2007. Biosynthesis of gold nanoparticles assisted by Escherichia coli DH5 $\alpha$ and its application on direct electrochemistry of haemoglobin. Electrochem. Commun. 9, 1165- 1170.

Guan, Q., Xia, C., Li, W., 2018. Graphical abstract SC Laboratory of Advanced Energy Materials Chemistry ( Ministry of Education ), Nankai. Catal. Today https://do. https://doi.org/10.1016/j.cattod.2018.05.004

Ibrahim, H.M.M., 2015. Green synthesis and characterization of silver nanoparticles using banana peel extract and their antimicrobial 
activity against representative microorganisms. J. Radiat. Res. Appl. Sci. 111. https://doi.org/10.1016/j.jrras.2015.01.007

Karthika, D., Vadakkan, K., Ashwini, R., Shyamala, A., 2015. Prodigiosin Mediated Biosynthesis of Silver Nanoparticles ( $\mathrm{Ag}$ NP's ) and Evaluation of its Antibacterial Efficacy. Int. J. Curr. Microbiol. Appl. Sci. 4, 868-874.

Klaus, T., Joerger, R., Olsson, E., Granqvist, C., 1999. Silverbased crystalline nanoparticles, microbially fabricated. Proc. Natl. Acad. Sci. USA. 96, 13611-13614.

Konishi, Y., Tsukiyama, T., Tachimi, T., Saitoh, N., Nomura, T., Nagamine, S., 2007. Microbial deposition of gold nanoparticles by the metal-reducing bacterium Shewanella algae. Electrochim. Acta. 53, 186-192.

Mahdieh, M., Zolanvari, A., Azimee, A., Mahdieh, M., 2012. Green biosynthesis of silver nanoparticles by Spirulina platensis. Sci. Iran. 19, 926-929.

Murphy, C., 2008. Sustainability as an emerging design criterion in nanoparticle synthesis and applications. J.Mater Chem 18, 2173-2176.

Okuyama, K., Lenggoro, W., Iwaki, T., 2004. Nanoparticle Preparation and Its Application, in: International Conference on MEMS. Nano and Smart Systems (ICMENS'04), IEEE. V. pp. $1-4$.

Phanjom, P., Sultana, A., Sarma, H., Ramchiary, J., Goswami, K., Baishya, P., 2012. Plantmediated synthesis of silver nanoparticles using Elaeagnus latifolia leaf extract. Dig. Nano. Biostru. 7, 1117 - 1123.

Pugazhendhi, A., Prabakar, D., Jacob, J.M., Karuppusamy, I., Saratale, R.G., 2017. Synthesis and characterization of silver nanoparticles using Gelidium amansii and its antimicrobial property against various pathogenic bacteria. Microb. Pathog. https://doi.org/10.1016/j.micpath.2017.11.01 3

Sadhasivam, S., Shanmugam, P., Veerapandian, M., Subbiah, R., Yun, K., 2012. "Biogenic syhtesis of multidimensional gold nanoparticles assisted by Streptomyces hygroscopicus and its electrochemical and antibacterial properties". Biometals, 25, 351360.

Shanmuga Praba, P., Vasantha, V., Jeyasundari, J., Brightson, J., Jacob, A., 2015. Synthesis of plant-mediated silver nanoparticles using ficus microcarpa leaf extract and evaluation of their antibacterial activities,. Eur. Chem. Bull. 4, 116-120.

Sharma, V., Kaushik, Sulochana, Pandit, P., Dhull, D., Yadav, J.P., Kaushik, Samander, 2018. Green synthesis of silver nanoparticles from medicinal plants and evaluation of their antiviral potential against chikungunya virus. Appl. Microbiol. Biotechnol. https://do.

Tharanya, P., Vadakkan, K., Hemapriya, J., Rajesh Kannan, V., Vijayanand, S., 2015. Biogenic Approach for the Synthesis of Titanium Dioxide Nanoparticles Using a Halophilic Bacterial Isolate - Chromohalobacter salexigens Strain PMT-1. Int. J. Curr. Res. Acad. Rev. 3, 334-342.

Thirumangai, S., Sudha, S., Karthic, R., Devakumar, J., 2015. In vitro evaluation of Silver nanoparticle synthesized from actinomycetes isolated from Noyal river basin. SIRJ-MBT. 2, 1-9.

Wagner, S., Gondikas, A., Neubauer, E., Hofmann, T., Kammer, F., 2014. Spot the Difference: Engineered and Natural Nanoparticles in the Environment-Release, Behavior, and Fate. Angew. Chem. Int. Ed. 53, $12398-12419$.

\section{How to cite this article:}

Ezhilvanan, M. and Lesley Sounderraj, S.F. 2019. Biogenic synthesis of silver nanoparticles mediated by Acinetobacter indicus and its biomedical applications. Int.J.Curr.Microbiol.App.Sci. 8(10): 2664-2676. doi: https://doi.org/10.20546/ijcmas.2019.810.308 